\title{
Conceptual Study of Techno-Stress on Women in Non-IT Sector
}

\author{
Ms. Koyel Mallick \\ M.Phil Research Scholar \\ Institute of Management Study \\ Kolkata, West Bengal, India
}

\begin{abstract}
Over past few months, teaching and technology experienced a special bond owning to the Covid-19 induced new normal. The use of Information and Communication Technology (ICT) tools in a work-from-home (WFH) scenario though proved prospective for many user/educators. In the hindsight, it has disrupted work-life balance causing counterproductive results. The stakes were high with inadequate training, fund allocation, unidentified strategies, skill deficit and scarce collaborative approaches in the teaching fraternity, further making it quite difficult for an educator to cope-up with sudden challenges to re-invent the teaching trends accordingly. Hence, in this milieu, fast gaining attention is idea of 'Technostress'. It is conceptually defined as any form of ICT that stimulates stress over the user striving to interact effectively through numerous technological platforms/ gadgets for a substantial span of time. Though past researchers had analyzed it with job satisfaction, employee performance, work load, behavioral stress and aspects of work-family conflict; a special treatment of women educators (in Indian context) undergoing the stress is awaited. In furtherance, education technology with its affinity towards pedagogy, educational policy administrators, technology developers and market are yet to identify women educators need exclusively. Together factors bearing stress under technology-overdrive with strategies to alleviate the same. Now, it is time to reckon women educator's need, ability, and interest, which should be mapped on optimum and effective use of technology.
\end{abstract}

Keywords: Technostress, Women Educator, Pandemic, ICT.

\section{Introduction}

Technology is the application of tested engineered tools on identified and / or observed phenomenon, which calls for optimizing human life/ comfort. Interestingly, in Information and Communication Technology (ICT), technology's need was felt to promote the ease and flexibility of information sharing through an inclusive communication medium. However, this much needed aid has been shaped singlehandedly by technocrats, commercial communities and policy makers, who somewhere failed to acknowledge and meet the needs of not-so-techno-centric 
beneficiaries (Stitch, Tarafdar \& Cooper, 2018). The resulting mismatch of need and resources had various manifestations, wherein the study shall discuss on one such issue focusing on Technostress for women academicians/ educators with respect to effect of ICT in this contemporary and pandemic situation.

In the contemporary times, it is quite pertinent to address this issue for extensive academic use of digital/ technical tools during pandemic and post-pandemic scenario. With respect to the demanding work-from-home (WFH) obligation the digital exposure/ lack of it (though a need-of-the-hour), can be perceived stressful. Technological Stress/ Technostress can be understood as perceived consequence of overindulgence above numerous technological platforms for a significant period of time, where the user strives to make the interaction effectively efficient. For any educator-user such a stress can be detrimental in many aspects. However, for the time being the study would get its focus validated through the definition by Wang, Shu and $\mathrm{Tu}$ in 2008, whereas technostress is stated as reflection of one's discomposure, fear, tenseness and anxiety when one is learning and using computer technology directly or indirectly that ultimately ends in psychological and emotional repulsion and prevents one from further learning or using computer technology.

\section{Technology \& Education: Contemporary Situation}

Now, in the twenty first century with education sector being identified by prospective developers as breeding ground for techno-race (Peeraer \& Van Petegem, 2015; Coklar et al. 2016), it has opened multiple possibilities. In furtherance, on one hand ICT competent teacher out of their own volition explore avenues of rejuvenating conventional teaching through technology, few educators with lesser digital literacy get bouts of stress and continue with their tested nontechnological techniques. This choice of the latter group of educators to steer away from digital option can be analyzed with an important research on technostress and academicians as indicated by Raghu-Nathan et al. in their research study. Also, they have stated that academicians suffer technostress with 'techno-overload, technoinvasion, techno-complexity, techno-insecurity, techno-uncertainty' as some of the causal components (Ragu-Nathan et al. 2008).

Moreover, the technostress has always been a companion with academic professionals with varying degree of effect on them (Estrada-Muñoz et al. 2020). Now, with this technostress in tow the contemporary pandemic times became a turning point for academics as digitalization of education and its effective use saw its exponential high. The academicians all across globe got diligently busy identifying best possible ways to blend technology and academics more out of compulsion than choice, which caused due to COVID-19 backdrop. Thus, it has become a stressful span for digitally-challenged educators who stumble at each odd encounter ranging from selecting the right digital platforms to efficiently utilizing 
existing tools like mobile, laptops, personal computer, tablets, software/ applications, etc. towards effectively transferring resource into study material catering to learner needs at the same time juggling between personal-professional demands (Estrada-Muñoz et al. 2020).

Interestingly, pandemic has not been the only cause for an advertent change, educator's sense of accountability played a catalytic role in making efforts in this testing time. Also, the term 'accountability' according to survey report of UNESCO '2019 World Teachers' Day Fact Sheet, states that teachers' comprehensible workload contributes to stress. Moreover, this responsibility substantially reinforces the technostress in the contemporary times as well. Being consciously aware of lacking self-efficacy in managing digital tools yet striving to meet expectation of contemporary learners (who themselves are highly techno-savvy), leads to stress, anxiety and psychological disorders among educators. 'Symptomatology' discusses about aberration in individuals, which fails his/her dexterity in ordering and assimilating of fresh information derived from Internet, resulting from 'mental fatigue' (Estrada-Muñoz et al. 2020). This can be threatening to the very cause of teaching-learning process in a techno-driven world where educators' role quickly transforms from being Educator to Facilitator. A study on challenges, perspectives and impact of ICT on teachers find learners becoming 'educational agents' (Harnandez, 2017), as they keep exchanging their roles with the educator to enhance learning process. Hence, an educator unable to prove technical competence and wandering through myriad digital platforms is no less menace. And the menace has already proven to invite 'technostress and job burnout into workplace' (Jena \& Mahanti, 2014), 'attitude, knowledge and anxiety' issues within the educatoracademics fold causing detrimental outcome (Imhof, Vollmeyer \& Beierlein, 2007; Coklar et al. 2016; Estrada-Muñoz et al. 2020).

\section{Objective}

To conceptually review and understand the technostress in accordance with working women's interface with ICT tools in academia.

\section{Need \& Relevance}

Research on Indian academicians by Jena and Mahanti in 2014 related technostress influences by demographic factors, found women academicians are less technostressed compared to the male counterparts. Their analysis finds women academicians using technology driven by need and men guided by inclination and thus more stressed. Discussing on the same note another group of researchers had found technostress in general resulting from over exposure to working around the ever-evolving digital devices at workplace, and with the zeal to be available and constantly erasing home and work spaces (Fritz, Park \& Jex, 2011). Also, women straddle home and workplace in most situations meeting demanding roles in both 
spheres. The role conflict in women can always thus align on this, where she finds juggling personal and professional responsibilities. But the situation has now aggravated for most WFH employees, women educators being one of them. To establish the connect, technostress factors in Teacher-ICT interface by yet another research team included: work load, work environment (Kinman \& Jones, 2005), changing technology and need for constant up-skilling (Fuglseth \& Sorebo, 2014; Karuppan, 1997; Smith \& Carayon, 2005; Coklar et al. 2016), erasure of workhome boundaries culminating in time management issues (Wang, Shu \& Tu, 2008; Coklar et al. 2016) as major setback. Undeniably, male educators may stand to lose in equal measures like the female counterpart. Still, studies on teacher-technostress aspect remains limited (Coklar et al. 2016).

\section{Rationale \& Niche}

The technostress has been an inseparable component in the recent times due to ICT dependent environment, which is more so in academia. Moreover, equipping to a complete ICT environment in general itself is difficult in complying with the modus operandi together executing the standards, alongside monitoring it has become the biggest challenge. These are the fundamental factors, which causes stress due to technological aspects. The women in educational sectors are experiencing this due to exertion in moderating their classes and subjects through online mode using communication devices periodically. However, it is a matter of discussion to what extent the technostress factors account for work-life imbalances. This signifies a study to be conducted exclusively on understanding the factors for technostress in women educators in Indian context which can have more evidences to inculcate the remedial prospects. Indian context because UNESCO 2019 World Teachers' Day Fact Sheet mentions on the basis of a global survey how there is alarming shortage of female/women educators in upper secondary school education. It specially mentions India where female teachers diminish by half with school's location stretching in remote geographical areas. The reasons listed by concerned study for shortage of female staff mentions the displacement settings, safety concerns and cultural practices. Though 2014 research of Jena and Mahanti did not see any significant impact of technostress upon marital status of academicians; there are some grey areas as far as 'cultural practices' and socio-cultural expectations from women and their multitude roles as daughter, wife/ homemaker, sister, teacher, caregiver, professional, etc. are concerned especially allied to Indian milieu.

\section{Suggestions}

The woman educator in a pandemic period braving through plethora of odds and challenges is also contributing into effective teaching-learning process. The research study in these lines shall help to streamline aids from human resource experts, technology developers, employers and policy administrators to devise better skill-enhancing ways to equip educators cope-up the technostress in the new 
normal. Thus, a full-fledged study has to be conducted on working women in different academia ranging from schools to varsities so as to understand the technostress issues and problems to a large extent. This will facilitate to understand the utility impact of ICT devices causing technostress on women workforces serving in educational sectors. Also, it will possibly provide an effective solution towards balancing it effectively through plausible measures.

\section{Conclusion}

The women workforces in educational sectors are subjected to technostress in the contemporary and pandemic scenarios, wherein the ICT utility has been increasing sequentially at all levels. Hence, technostress becomes unavoidable aspect in the current trends, which has its impact more so with women. The reason being women have multifaceted roles and often subjected to stressors at all spheres of life especially in workplace, which demands holistic outputs amidst pandemic. This in turn makes them to experience technostress at large, wherein they tend to have imbalances. The congregation of diverse research studies addressing women's work-life balance measures has become the sheer necessity to focus for appropriate measures to achieve prospects.

\section{References}

Coklar, A. N., Efilti, E., Sahin, Y. L. \& Akcay, A. (2016). Investigation of TechnoStress Levels of Teachers Who Were Included in Technology Integration Processes, Turkish Online Journal of Educational Technology, pp.1331-1339.

Estrada-Muñoz, C., Castillo, D., Vega-Muñoz, A. \& Boada-Grau, J. (2020). Teacher Technostress in the Chilean School System, International Journal of Environmental Research and Public Health, Vol.17, No.15, 5280.

Fritz, C., Park, Y. \& Jex, S. M. (2011). Relationship between Work-Home Segmentation and Psychological Detachment from Work: The Role of Communication Technology use at Home, Journal of Occupational Health Psychology, Vol.16, No.4, pp.457-467.

Fuglseth, A. M. \& Sorebo, O. (2014). The Effects of Technostress Within the Context of Employee Use of ICT, Computers in Human Behavior, Vol.40, pp.161-170.

Hernandez, R. M. (2017). Impact of ICT on Education: Challenges and Perspectives, Purposes and Representations, Vol.5, No.1, pp.325-347. 
Imhof, M., Vollmeyer, R. \& Beierlein, C. (2007). Computer Use and the Gender Gap: The Issue of Access, Use, Motivation and Performance, Computer in Human Behaviour, Vol.23, pp.2823-2837.

Jena, R. K. \& Mahanti, P. K. (2014). An Empirical Study of Technostress among Indian Academicians, International Journal of Education and Learning, Vol.3, No.2, pp.1-10.

Karuppan, C. M. (1997). Advanced Manufacturing Technology and Stress: Technology and Management Support Policies, International Journal of Technology Management, Vol.14, No.2-4, pp.254-264.

Kinman, G. \& Jones, F. (2005). Lay Representations of Workplace Stress: What do People Really Mean When They Say They are Stressed? Work and Stress, Vol.19, No.2, pp.101-120.

Peeraer, J. \& Van Petegem, P. (2015). Integration or Transformation? Looking in the Future of Information and Communication Technology in Education in Vietnam, Evaluation and Program Planning, Vol.48, pp.47-56.

Ragu-Nathan, T. S., Tarafdar, M., Ragu-Nathan, B. S. \& Tu, Q. (2008). The Consequences of Technostress for End Users in Organizations: Conceptual Development and Empirical Validation, Information System Research, Vol.19, No.4, pp.417-433.

Smith, M. J. \& Carayon, P. (1995). New Technology, Automation, and Work Organization: Stress Problems and Improved Technology Implementation Strategies, International Journal of Human Factors in Manufacturing, Vol.5, No.1, pp.99-116.

Stitch, J. F., Tarafdar, M. \& Cooper, C. S. (2018). Electronic Communication in Workplace: Boon or Bane? Journal of Organizational Effectiveness: People and Performance, Vol.5, No.1, pp.98-106.

Wang, K., Shu, Q. \& Tu, Q. (2008). Technostress under Different Organizational Environments: An Empirical Investigation, Computers in Human Behavior, 24, pp.3002-3013

\section{Bibliography}

Ahmad, U. N., Amin, S. M. \& Ismail W. K. W. (2009). The Impact of Technostress on Organizational Commitment among Malaysian Academic Librarians, Singapore Journal of Library \& Information Science. Vol.38, pp.103-123. 
Basargekar, P. \& Singhavi, C. (2017). Factors Affecting Teachers' Perceived Proficiency in Using ICT in the Classroom, IAFOR Journal of Education, Vol.5, No.2, pp.67-84.

Ennis, L. A. (2005). The Evolution of Technostress, Computers in Libraries, Vol.25, No.8, pp.10-12.

\section{Webliography}

https://en.unesco.org/gem-report/report/2017/accountability-education

http://uis.unesco.org/sites/default/files/documents/world-teachers-day-2019-fact sheet.pdf

https://www.mhrd.gov.in/sites/upload_files/mhrd/files/India_Report_Digital_Educa tion_0.pdf

https://www.varkeyfoundation.org/media/5484/ag-system-failure.pdf 